\title{
Gadolinium retention and clearance after administration of macrocyclic magnetic resonance contrast agents to rats
}

\author{
Simona Bussi ${ }^{1} \cdot$ Federico Maisano $^{1} \cdot$ Fabio Tedoldi ${ }^{1} \cdot$ Miles A. Kirchin ${ }^{1}$ (i)
}

Received: 9 April 2019 /Revised: 9 April 2019 / Accepted: 21 May 2019/Published online: 1 July 2019

(C) The Author(s) 2019

\section{Dear Editors,}

We read with interest the article by Dr. Blumfield et al. [1] in the March 2019 issue of Pediatric Radiology on MR signal intensity changes and tissue gadolinium (Gd) retention, with emphasis on pediatric patients. On page 454 the authors reported the results of a study by Bussi et al. [2], making the following statement: "A recent study by Bussi et al. [68] compared the three macrocyclic agents Dotarem, ProHance and Gadovist in rats that were sacrificed 28 days following multiple administrations of one of these GBCAs. The authors found significantly lower concentrations of gadolinium in rats injected with Dotarem when compared to the other two agents, in the cerebrum, cerebellum, femur and renal tissues." Later, on the same page, the authors stated the following: "Furthermore there are differences between macrocyclic agents that are related to their chemical stability, with a higher clearance rate of Dotarem, which is ionic and hence more stable than ProHance and Gadovist." These statements are factually incorrect.

In the study in question, Bussi et al. [2] made 20 repeated administrations of ProHance (gadoteridol; Bracco Diagnostics Inc., Milan, Italy), Dotarem (gadoterate meglumine; Guerbet LLC, Villepinte, France) or Gadovist (gadobutrol; Bayer, Leverkusen, Germany) to rats (15/group) and then determined gadolinium levels in the cerebrum, cerebellum, liver, kidneys, skin and blood by inductively coupled plasma-mass spectrometry (ICP-MS) after a 28-day recovery period. Contrary to the statement of Dr. Blumfield et al. [1], Bussi et al. showed significantly lower levels of gadolinium in all soft-tissue organs

Miles A. Kirchin

miles.kirchin@bracco.com

1 Bracco Imaging SpA,

Via Caduti Di Marcinelle,

20134 Milan, Italy after the cumulative administration of ProHance than after Dotarem or Gadovist: $0.150 \pm 0.022$ vs. $0.292 \pm 0.057$ and $0.287 \pm 0.056 \mathrm{nmol} / \mathrm{g}$, respectively $(P<0.001)$, in the cerebellum; $0.116 \pm 0.036$ vs. $0.250 \pm 0.032$ and $0.263 \pm 0.045 \mathrm{nmol} / \mathrm{g}$, respectively $(P<0.001)$, in the cerebrum; $25 \pm 13$ vs. $139 \pm 88$ $(P<0.01)$ and $204 \pm 109 \mathrm{nmol} / \mathrm{g}(P<0.001)$, respectively, in the kidneys. Significantly $(P<0.001)$ higher gadolinium levels were noted in the femur with Gadovist $(8.60 \pm 2.04 \mathrm{nmol} / \mathrm{g})$ compared to Dotarem $(5.69 \pm 1.75 \mathrm{nmol} / \mathrm{g})$ while the mean value for ProHance $(7.48 \pm 1.37 \mathrm{nmol} / \mathrm{g})$ was only marginally significantly higher than the mean value for Dotarem $(P<0.05)$.

It is worth emphasizing that other authors have similarly found lower levels of gadolinium in rat brain and body tissues after administration of ProHance compared to Dotarem and Gadovist, particularly in the first days and weeks after administration, indicating a more rapid clearance of ProHance than Dotarem or Gadovist [3, 4]. The differential clearance appears to reflect differences in the specific molecular properties of the agents rather than any effect of stability [5]. If animal studies are to be taken as indicative of the situation in humans, as Dr. Blumfield et al. [1] implied, then it is worth noting the vast differences in time-scale between the two species, with 1 rat year corresponding to approximately 30 human years [6]. This means that gadolinium levels measured at 28 days after the last contrast administration in the study by Bussi et al. [2] would equate to almost 2.5 years in human terms. This might be particularly relevant for MRI of pediatric subjects.

In conclusion, Dr. Blumfield et al. [1] have misunderstood the results of the study by Bussi et al. [2] and need to correct and clarify their statements to avoid misinformation and misinterpretation.

\section{Compliance with ethical standards}

Conflicts of interest The authors are all employees of Bracco Imaging. 
Open Access This article is distributed under the terms of the Creative Commons Attribution 4.0 International License (http:// creativecommons.org/licenses/by/4.0/), which permits unrestricted use, distribution, and reproduction in any medium, provided you give appropriate credit to the original author(s) and the source, provide a link to the Creative Commons license, and indicate if changes were made.

\section{References}

1. Blumfield E, Swenson DW, Iyer RS, Stanescu AL (2019) Gadolinium-based contrast agents - review of recent literature on magnetic resonance imaging signal intensity changes and tissue deposits, with emphasis on pediatric patients. Pediatr Radiol 49:448 457

2. Bussi S, Coppo A, Botteron C et al (2018) Differences in gadolinium retention after repeated injections of macrocyclic MR contrast agents to rats. J Magn Reson Imaging 47:746-752
3. Jost G, Frenzel T, Boyken J et al (2019) Long-term excretion of gadolinium-based contrast agents: linear versus macrocyclic agents in an experimental rat model. Radiology 290:340-348

4. McDonald RJ, McDonald JS, Dai D et al (2017) Comparison of gadolinium concentrations within multiple rat organs after intravenous administration of linear versus macrocyclic gadolinium chelates. Radiology 285:536-545

5. Aime S (2019) Differences in molecular structure markedly affect GBCA elimination behavior. Radiology 291:267-268

6. Sengupta $P$ (2013) The laboratory rat: relating its age with human's. Int J Prev Med 4:624-630

Publisher's note Springer Nature remains neutral with regard to jurisdictional claims in published maps and institutional affiliations. 